\title{
Nonsteroidal anti-inflammatory drugs: prostaglandins, indications, and side effects
}

This article was published in the following Dove Press journal:

International Journal of Interferon, Cytokine and Mediator Research

27 January 2011

Number of times this article has been viewed

\section{Ippokratis Pountos' \\ Theodora Georgouli' \\ Howard Bird ${ }^{2}$ \\ Peter V Giannoudis'}

'Academic Department of Trauma and Orthopaedics, School of Medicine,

${ }^{2}$ Section of Musculoskeletal Disease, Leeds Institute of Molecular Medicine, University of Leeds, Leeds, UK
Correspondence: PeterV Giannoudis Academic Department of Trauma and Orthopaedics, Leeds Teaching Hospitals NHS Trust, Clarendon Wing, Great George St, Leeds LSI 3EX, UK Tel +44 II 33922750

Email pgiannoudi@aol.com

\begin{abstract}
For centuries, nonsteroidal anti-inflammatory drugs (NSAIDs) have been part of our clinical practice. They started out as drugs with anti-inflammatory and analgesic action, and gradually their use has been expanded to new therapeutic targets, some of which are unrelated to their primary mode of action. Today, our armamentarium includes a large range of compounds, attesting to their utility in the treatment of clinical pathologies ranging from pain and inflammation to prevention and treatment of cancer. On the other hand, although NSAIDs share many common properties, their use poses risks, and physicians should be cognizant of their subtle differences and potential complications. In this context, this review article presents insight into NSAIDs' pathophysiology and mode of action in the clinical setting, their indications, and their potential side effects.
\end{abstract}

Keywords: nonsteroidal anti-inflammatory drugs, prostaglandins, COX

\section{Introduction}

Nonsteroidal anti-inflammatory drugs (NSAIDs) have their origin in the extracts of salicylate-containing plants initially described in ancient Roman and Greek literature. ${ }^{1}$ In particular, the extracts of willow tree were known for their antipyretic, analgesic, and anti-inflammatory properties. ${ }^{2}$ For many centuries, there was no real progress until advances made in chemistry over a century ago that enabled the synthesis of salicylic and acetylsalicylic acids. ${ }^{1}$ In the early 1960 s, indomethacin and ibuprofen were developed, and their use increased as a result of their being approved for over-the-counter sale. ${ }^{1}$ Several other molecules were discovered; however, their mechanism of action eluded scientists until 1971 (Table 1). In the same year, Sir John Vane demonstrated the inhibition of the enzymatic production of prostaglandins by NSAIDs. ${ }^{3}$ A major setback occurred in 2004 with the worldwide withdrawal of rofecoxib and valdecoxib due to the apparent high risk of myocardial infarction. ${ }^{1}$ Nevertheless, NSAIDs today are one of the most commonly used medications. Approximately $70 \%$ of people aged 65 years or older are reported to use NSAIDs at least once per week. ${ }^{4}$ In the US alone, more than 111 million prescriptions are issued annually, at an approximate cost of $\$ 4.8$ billion. $^{5}$

\section{Mechanism of action of NSAIDs Biosynthesis of prostaglandins and leukotriene pathway} It is more than 80 years since prostaglandins were identified in the human body. ${ }^{6}$ They were first described by Goldblatt as substances produced by the prostate gland and contained in the seminal fluid, with antihypertensive properties. ${ }^{6}$ Later, it was 
Table I Nonsteroidal anti-inflammatory drugs by class ${ }^{1,18,88}$

\begin{tabular}{ll} 
Class & Drug \\
\hline Salicylates & - Aspirin (acetylsalicylic acid) \\
& - Salsalate \\
- Diflunisal \\
Nonacetylated salicylates & - Magnesium salicylate \\
Propionic acid derivatives & - Iboline magnesium trisalicylate \\
& - Ketoprofen \\
& - Naproxen \\
& - Fenoprofen \\
& - Flurbiprofen \\
Fenamates & - Oxaproxin \\
Indoles & - Mefenamic acid \\
& - Meclofenamate sodium \\
Oxicams & - Indomethacin \\
Phenylacetic acids & - Sulindac \\
Pyrazole derivatives & - Tometin sodium \\
Pyrrolo-Pyrrole & Piroxicam \\
Pyranocarboxyl acid & - Meloxicam \\
\hline
\end{tabular}

shown that prostaglandins are formed by a great variety of cells within the human body. ${ }^{2}$ Their effect is complex and depends on the type of target cell. ${ }^{2}$ The exact role of every individual prostaglandin is still unclear, as in time the same compound could exert different or even opposite responses to the target cells. ${ }^{2}$

During the biosynthesis of prostaglandins, cyclooxygenase ( $\mathrm{COX}$ or prostaglandin $\mathrm{H}$ synthase) catalyses the conversion of arachidonic acid to the prostaglandin endoperoxidases, prostaglandin $\mathrm{G}_{2}\left(\mathrm{PGG}_{2}\right)$, and then $\mathrm{PGH}_{2}$ (Figure 1). ${ }^{7,8} \mathrm{PGH}_{2}$ is the precursor of the biologically active prostaglandins and thromboxanes. $\mathrm{PGH}_{2}$ is then isomerized into various prostanoids such as thromboxane $\mathrm{A}_{2}\left(\mathrm{TXA}_{2}\right)$, prostacyclin $\left(\mathrm{PGI}_{2}\right), \mathrm{PGD}_{2}, \mathrm{PGE}_{2}$, and $\mathrm{PGF}_{2 \mathrm{a}}{ }^{7,8}$

Along with the prostaglandin pathway, the leukotrienes pathway is a strong mediator of inflammation. It involves the conversion of arachidonic acid to 5-hydroperoxyeicosatetranoid acid (5-HPETE) (Figure 1). ${ }^{9}$ 5-HPETE is then catalyzed, forming an unstable epoxide, the leukotriene A4 $\left(\mathrm{LTA}_{4}\right)$. The latter is further catalyzed to either leukotrienes $\mathrm{B}_{4}$ or $\mathrm{C}_{4}$. LTC $_{4}$ might be converted to $\mathrm{LTD}_{4}$, which can be further converted to $\mathrm{LTE}_{4}$. The LTC $\mathrm{LTD}_{4}$, and $\mathrm{LTE}_{4}$ are called peptidoleukotrienes or cysteinyl leukotrienes. Involvement of the leukotriene pathway contributing to the unwanted effect of NSAIDs has also been postulated. Diverted arachidronate to this pathway after inhibition of COX by NSAIDs causes increased formation of leukotrienes, which are also mediators of inflammation. ${ }^{1}$ Among these, $\mathrm{LTB}_{4}$ is involved in inflammatory processes causing neutrophil, monocyte, and eosinophil chemotaxis, neutrophil degranulation, and lysosomal enzyme release, as well as modulation of pain and immune responses. ${ }^{1}$ $\mathrm{LTB}_{4}$ levels have been found to be elevated in patients with rheumatoid arthritis and have been implicated in chronic inflammation and joint destruction. ${ }^{10}$ In addition, the cysteinyl leukotrienes have powerful spasmogenic action, especially in airway smooth muscles and vasculature, and are released during asthmatic attacks, inflammation, hypersensitivity reactions, and rheumatoid arthritis. ${ }^{9}$ Leukotrienes can also cause vasoconstriction of the gastric mucosa and increase formation of reactive radicals, which can cause gastrointestinal (GI) mucosal lesions., ${ }^{9,10}$ This suggests that the blockage of the protective prostaglandins by the NSAIDs could result in further toxicity by the products of leukotriene pathway.

\section{NSAIDs as inhibitors of COX-I and COX-2}

There are two COX enzymes: COX-1 and COX-2. ${ }^{11}$ These proteins are structurally distinct, have the same molecular weight, and show $60 \%$ homology of their DNA. ${ }^{12}$ Their difference resides in their substrate binding sites, which are smaller in COX-1 than in COX-2. ${ }^{12}$ The active site of COX lies in a narrow hydrophilic tunnel composed of an active inner site and protected by an outer area that is made up of three $\alpha$ helices. NSAIDs attach to these outer helices and temporarily prevent the passage of arachidonic acid from reaching the active site and triggering the production of prostaglandins. ${ }^{13} \mathrm{COX}-1$ is constitutively expressed in most cells and is involved in physiological processes. In the GI tract, prostacyclin and $\mathrm{PGE}_{2}$ exert a protective effect by reducing acid secretion, vasodilatation of blood vessels of gastric mucosa, and stimulation of mucus production, which acts as a barrier. ${ }^{14}$ In the kidneys, prostaglandins play a key role in regulating blood flow and enhancing organ perfusion. ${ }^{14} \mathrm{COX}-1$ expression is also found in fetal and amniotic cells, uterine epithelium in early pregnancy, and the central nervous system and is believed to exert complex integrative functions. ${ }^{15}$ On the other hand, COX-2 was considered to be induced by inflammation and the presence of proinflammatory cytokines and mitogens. ${ }^{16}$ It has been suggested that the anti-inflammatory action of NSAIDs is due to the inhibition of COX-2, whereas COX-1 inhibition is associated with unwanted effects related to interference of the regulatory and protective mechanisms. ${ }^{16,17}$ However, recent studies have indicated that $\mathrm{COX}-2$ is also constitutively 


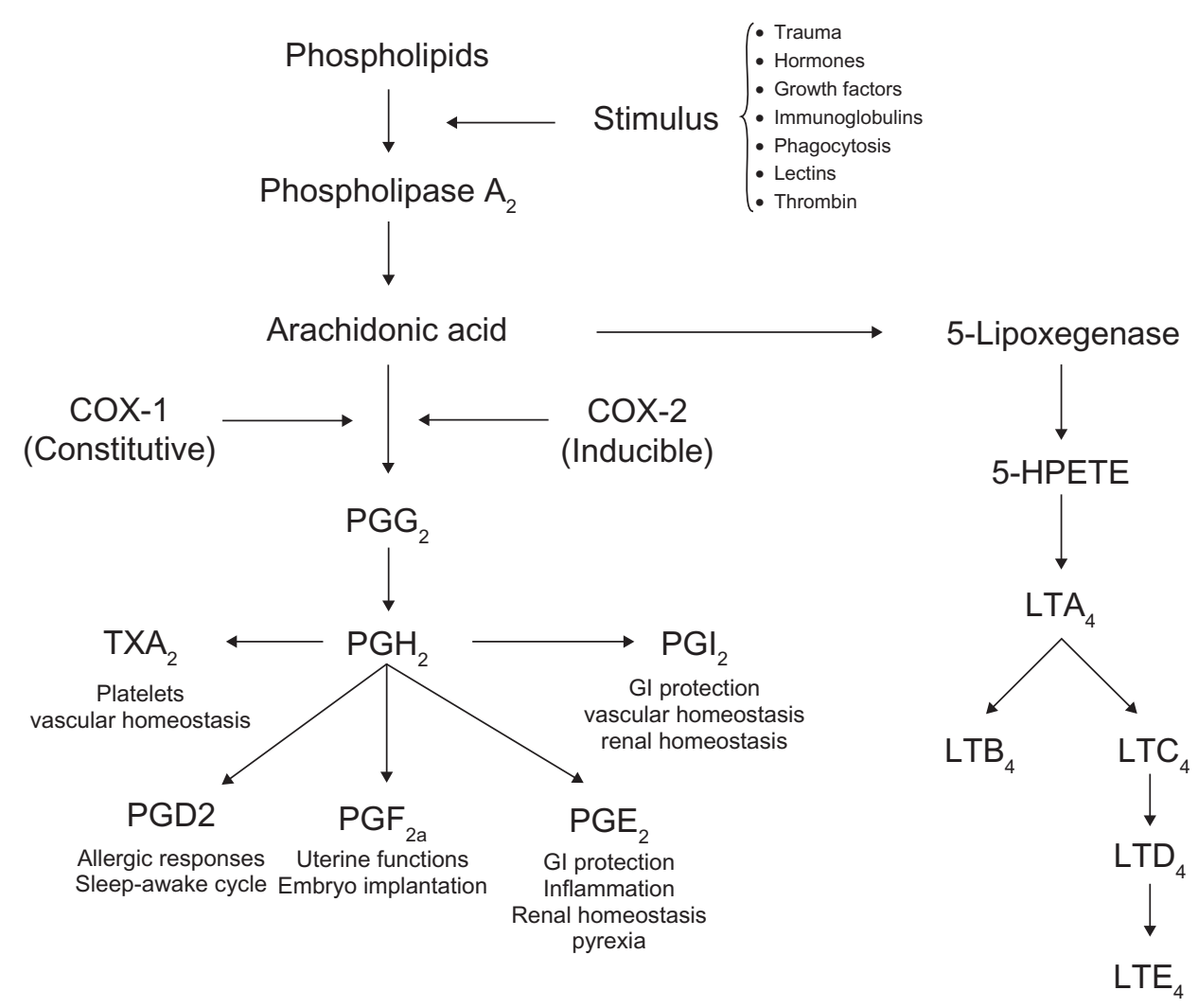

Figure I The arachidonic acid cascade.

expressed in the brain and, in particular, in the hippocampus and cortical glutaminergic neurons, as well as in the kidneys, uterus, and prostate. ${ }^{18,19}$ Similarly, COX-1, despite its constitutive expression, is shown to participate in inflammation (eg, lipopolysaccharide-induced inflammation) where it might be inducible. ${ }^{20}$

There has been much speculation and interest in the possibility that other COX enzymes exist in addition to COX-1 and COX-2.21,22 COX-3 was investigated by researchers who mainly studied the enigmatic mode of action of weak COX-1 and COX-2 inhibitors like acetaminophen, which exerts reduction of pain and fever with virtually no anti-inflammatory effects but with good penetration into the central nervous system. ${ }^{21,22}$

NSAIDs also affect processes other than prostaglandin inhibition. Within the cell membrane, they are involved in the oxidation of nicotinamide adenine dinucleotide phosphate in neutrophils. ${ }^{23}$ This action results in direct inhibition of neutrophil functions. High doses of NSAIDs have also been found to inhibit proteoglycan synthesis, cell-to-cell binding, and transmembrane ion fluxes. Furthermore, NSAIDs have been found to unmask T-cell suppressor activity, leading to a reduction in rheumatoid factor. ${ }^{23}$

Several ranking systems have been developed in categorizing NSAIDs according to their selectivity. $\mathrm{IC}_{80}$ (ie, the concentration required to inhibit $80 \%$ of COX activity) ranking assay is based on the drug concentration needed to inhibit $80 \%$ of COX-1 or COX-2. ${ }^{24}$ In this system, the drugs are ranked based on the ratio between the amounts of drug needed to inhibit COX-2 compared with COX-1. Other assays measure the $\mathrm{IC}_{50}$ or the thromboxane $\mathrm{B}_{2}$ to $\mathrm{PGI}_{2}$ ratio. ${ }^{24,25}$ Brooks et al compared these different assays and found a high degree of variability, suggesting that the reported COX-2/COX-1 ratios, although indicative, are in many cases misleading. ${ }^{25}$ For instance, they found that the reported range of COX-2 selectivity varied between 0.067 and 4 for diclofenac, 1.3 and 107.1 for indomethacin, 9.4 and 600 for piroxicam, 0.67 and 53.3 for ibuprofen, and 2 and 167 for aspirin. According to the results of various studies on the ranking scheme in terms of COX-2 selectivity, one can consider rofecoxib, celecoxib, and meloxicam as posing the higher COX-2 selectivity, followed by ibuprofen, diclofenac, and piroxicam. ${ }^{24,25}$ Aspirin, indomethacin, and ketorolac have the lowest COX-2 selectivity. ${ }^{24,25}$

\section{Uses of NSAIDs}

\section{NSAIDs in acute and chronic pain}

NSAIDs have a wide range of indications, especially in cases where pain and inflammation are present (Table 2) 
Their effectiveness is well proven by their everyday use in such settings, with pronounced analgesic potency and fewer side effects compared with other agents. ${ }^{26,27}$ However, it is worthwhile mentioning that this effect is indirect and is exerted by the increase of the sensitivity of nociceptors to stimuli derived from traumatized or inflamed tissue. ${ }^{2}$ They switch normally nonexcitable polymodal receptors into a state in which they can be easily excitable. ${ }^{2}$

In an acute and postoperative pain setting, NSAIDs are widely used, primarily to target mild and moderate pain. ${ }^{28}$ Several authors suggest that NSAIDs should be used as the first line of treatment in pain therapy and recommend that opioids should be added only if pain is not controlled adequately with NSAIDs alone. ${ }^{28}$ There is insufficient evidence that a specific type of NSAID is more effective than others in this setting. ${ }^{28}$ Studies comparing opiates with NSAIDs show that NSAIDs are at least as effective as opiates, with some studies suggesting that NSAIDs can achieve greater reductions in pain scores. ${ }^{29-32}$ These patients are less likely to require further analgesia in the short term than those receiving opioids. ${ }^{29}$ Furthermore, it should be mentioned that the side effects of narcotic analgesics, such as respiratory depression, sedation, and cognitive effects, as well as constipation, can be avoided or minimized. ${ }^{33}$ For postoperative patients, this can be translated into decreased hospital stay, allowing early mobilization and weight bearing. ${ }^{29,34}$

One could say that NSAIDs' superiority over other painkilling approaches lies in the multiple ways that they can be used. Besides the traditional approach, NSAIDs can be used pre-emptively, ie, before prostaglandin release or topically, providing higher concentrations locally at the area of inflammation. A pre-emptive, multimodal, perioperative analgesic regimen is based on the principle that two or more agents acting at different levels are used before surgery to

Table 2 Most common indications for nonsteroidal antiinflammatory drug use ${ }^{89}$

- Mild-to-moderate pain due to inflammation and tissue injury

- Sprains, strains, and rheumatism

- Back pain and sciatica

- Osteoarthritis and rheumatoid arthritis

- Acute gout

- Inflammatory arthropathies (eg, ankylosing spondylitis, psoriatic arthritis, Reiter's syndrome)

- Dysmenorrhea, headache, and migraine

- Postoperative pain

- Renal and biliary colic

- Antipyretic

- Other inflammatory conditions improve pain levels after surgery. ${ }^{35,36}$ In fact, this model has been studied in patients undergoing major orthopedic procedures, and results showed decreased postoperative narcotic requirements with decreased hospital stay and earlier rehabilitation. ${ }^{35,36}$ Topical NSAIDs penetrate the skin and distribute to the target tissues that lie underneath the application site. ${ }^{37}$ The pharmacologically effective dose is delivered at the inflamed site, and there is minimal systemic absorption; therefore, the risk of related adverse events is low. ${ }^{37,38}$ They represent a convenient, effective, and safer form of pain relief, and they are an attractive option, particularly considering current concerns about the safety of traditional NSAIDs and COX-2 inhibitors. ${ }^{37,38}$

Chronic pain derived from joint destruction continues to be one of the biggest causes of disability and loss of function worldwide. In this setting, NSAIDs relieve pain and reduce swelling and stiffness. ${ }^{23,39,40}$ As a result, these patients have improved mobility with increased joint function and grip strength. ${ }^{39,40}$ This effect is only palliative and has not shown to permanently arrest or reverse the underlying disease process. In such cases, disease-modifying antirheumatic drugs like azathioprine, infliximab, and methotrexate may be considered. ${ }^{23}$ Although COX-2 selective NSAIDs have been developed to target the management of chronic pain, it became clear that these drugs have the same symptomatic relief as the non-selective NSAIDs, but COX-2 provides better GI tolerability and fewer GI-related side effects. ${ }^{41,42}$ The Celecoxib versus Omeprazole and Diclofenac in patients with Osteoarthritis and Rheumatoid Arthritis (CONDOR) trial has shown that COX-2 NSAIDs pose less risk for GI events than a nonspecific NSAID plus a proton pump inhibitor (PPI) (omeprazole). ${ }^{41}$ In ankylosing spondylitis, continuous NSAIDs seem to prevent progression of structural damage possibly due to retardation of osteoproliferation and have a high symptomatic efficacy. ${ }^{43,44}$

\section{NSAIDs usage not related to analgesia and arthritis}

Over the last three or four decades, observations have suggested that NSAIDs can be involved in the treatment of conditions unrelated to chronic inflammation or painful states. The first observation suggested that aspirin, but not salicylate, inhibited the activation and aggregation of platelets..$^{45}$ Later, it became clear that, unlike other NSAIDs, aspirin induces a long-lasting covalent and irreversible inhibition of COX enzyme and thus inhibits platelet TXA $_{2}$ biosynthesis. ${ }^{45,46}$ The activation and aggregation of platelets are the nidus for thrombus formation; therefore, aspirin's unique effect has 
been exploited in the prevention of thromboembolic and vascular diseases. ${ }^{46}$

The NSAID properties related to tumor inhibitions and prevention of metastasis are less clear. Several studies have suggested that the abundant production of prostaglandins and cytokines produced by the tumors is a key factor for their metabolism and proliferation, as well as the angiogenesis, tumor invasion, resistance to apoptosis, and suppression of antitumor immunity. ${ }^{47-49}$ Therefore, their inhibition by NSAIDs has favorable results. ${ }^{47}$ More difficult to explain is the protective effect of NSAIDs against tumors. NSAIDs were reported to reduce the incidence of tumors, including gastric, lung, brain, breast, and biliary tract tumors. ${ }^{50}$ This mode of action is still poorly understood and is regarded as a non-COX effect of NSAIDs.

Other uses of NSAIDs include the prevention of Alzheimer's disease, a finding that was based on epidemiological studies but was failed to be reproduced with clinical trials. ${ }^{51}$ Furthermore, a potential protective role of aspirin-like analgesics against cataract was suggested, with some studies reporting a $50 \%$ reduction in the risk of cataract formation..$^{52,53}$

\section{NSAIDs adverse effects}

\section{Risk factors}

NSAIDs' clinical utility is a fine balance between therapeutic efficacy and toxicity. Several risk factors for increased toxicity have been identified, and a number of clinical characteristics have been associated with a higher risk for complications. ${ }^{5,12,23,54}$ The most important risk factor includes a history of pre-existing GI complications, age, concomitant anticoagulation therapy, and high-dose NSAIDs or multiple NSAIDs. ${ }^{5,12,23,54}$ Table 3 presents the different risk factors and their relative risk. It is worth mentioning that the presence of Helicobacter pylori does not seem to be a risk factor for ulcer in conjunction with NSAID use. ${ }^{5}$ When risk factors are present, the indication for NSAID therapy should be scrutinized, and, if appropriate, prophylactic medication and close follow-up should be considered.

\section{Gl}

The best-known side effect of NSAID use is GI toxicity, which is the primary limiting factor for their use. It can be categorized into three groups. The first group includes mild GI disturbances including nausea, dyspepsia, heartburn, and abdominal pain or cramps. ${ }^{5,55}$ They can occur in $20 \%-40 \%$ of NSAID users, but such symptoms correlate poorly with the development of endoscopic injury or clinical events. ${ }^{55,56}$ More severe symptoms are found in the second group derived from
Table 3 Risk factors for upper gastrointestinal tract (GI) clinical events with nonsteroidal anti-inflammatory drug (NSAID) use criteria for preventive therapies ${ }^{22,29,49,59}$

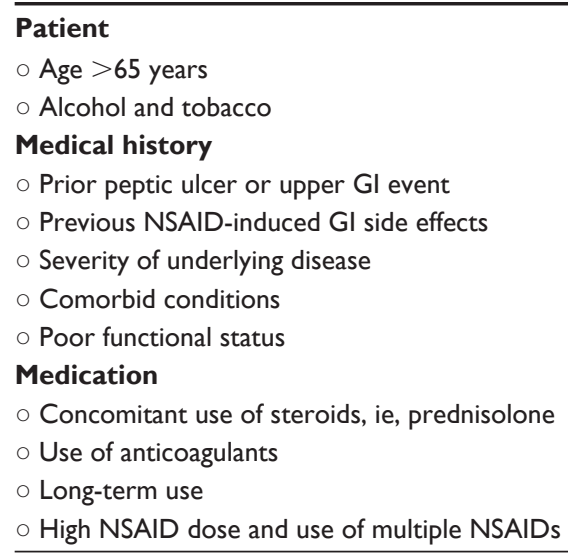

Abbreviations: Gl, gastrointestinal tract; NSAIDs, nonsteroidal anti-inflammatory drugs.

GI mucosal erosions and asymptomatic ulcers, which may heal spontaneously. The third group includes symptomatic ulcers with or without bleeding, which in some cases can be life-threatening. ${ }^{2,57}$ The last group occurs in $\sim 1 \%-2 \%$ of NSAID users and has a mortality rate of $10 \% .{ }^{57}$ It is worth mentioning that this annual incidence of $1 \%$ translates into an annual occurrence of $\sim 140,000$ NSAID-related complications in the US. ${ }^{2}$

Many gastroprotective strategies have been studied in terms of efficacy to prevent NSAID GI complications. ${ }^{45}$ The concomitant use of PPIs or histamine $\mathrm{H}_{2}$ receptor antagonists has been shown to decrease the incidence of NSAID ulcers but not the severe GI complications. ${ }^{58}$ Likewise, concomitant use of prostaglandin E analogs (misoprostol) reverses the gastrotoxic effect of NSAIDs, reducing the asymptomatic lesions by $90 \%$, but it can also reduce ulcer bleeding by $40 \%{ }^{45,59}$ Unfortunately, the discontinuation rate of misoprostol is high, as it is frequently poorly tolerated due to symptoms like diarrhea and abdominal pain. . $^{245,59}$

\section{Acute kidney injury and hypertension}

Renal vasodilator prostaglandins, among other effects, maintain renal blood flow and glomerular filtration rates. This effect is mainly exerted by them relaxing preglomerular resistance and acting as angiotensin II and norepinephrine antagonists. Therefore, NSAIDs usage can cause a variable degree of renal dysfunction, ranging from a reversible impairment of glomerular filtration rate to irreversible renal damage. ${ }^{60-63}$ Following newly initiated NSAIDs therapy, the incidence for renal impairment is higher within the first 4-6 weeks, and it is estimated that in this period of time, 1 in 
200 patients aged more than 65 years develop acute renal injury. ${ }^{60,61}$ Among NSAIDs, indomethacin posed the highest risk, with ibuprofen, piroxicam, and celecoxib also exhibiting high risk. ${ }^{63}$ Celecoxib poses the lowest risk compared with other NSAIDs, suggesting a marked gradient of risk among different NSAIDs. ${ }^{60,61}$ NSAID use has also been associated with acute interstitial nephritis, membranous nephropathy, and nephritic syndrome; however, the underlying pathophysiology remains unknown. ${ }^{62}$

Renal prostaglandins also affect the systemic vascular resistance. The result from this effect is an elevation in blood pressure that can be as high as $6 \mathrm{~mm} \mathrm{Hg} .{ }^{64}$ The risk is higher with selective COX-2 NSAIDs compared with nonselective COX-2 NSAIDs and placebo. ${ }^{64}$ Among the COX-2 selective NSAIDs, great variability exists with more potent effect obtained by rofecoxib and etoricoxib. ${ }^{65}$ Several studies found that the relative risk for developing hypertension with NSAIDs varies from $\sim$ two-fold to three-fold compared with nonusers. ${ }^{64,65}$

\section{Cardiovascular effects}

Recently, there has been much focus on NSAIDs, particularly on COX-2 inhibitors, not because of their gastroprotective effect but because of the increasing evidence that their use is associated with cardiovascular (CV) adverse events. Although the exact mechanism is not fully understood, it seems to be linked to the relative imbalance in $\mathrm{PGI}_{2}$ and $\mathrm{TXA}_{2}$ production, resulting in a prothrombotic state. ${ }^{66-68}$ This has been investigated with a number of studies to date, which showed that the use of COX-2 inhibitors is associated with an elevated risk of CV events in high-risk patients. ${ }^{67}$ Graham et al has shown that patients receiving $<25 \mathrm{mg}$ /day of rofecoxib had a 1.49-fold risk of developing acute myocardial infarction compared with those receiving celecoxib, and this risk increases to 3.58-fold for patients receiving more than $25 \mathrm{mg}$ daily. ${ }^{69}$ It is noteworthy that even short-term exposure was not risk free. ${ }^{3}$ Two largescale trials, the Adenomatous Polyp Prevention on Vioxx (APPROVe) trial and the Adenoma Prevention with Celecoxib (APC) trial, with 2586 and 2035 participants, respectively, are worth mentioning. ${ }^{67,68}$ The APPROVe trial showed a 1.9-fold increase in risk of thrombotic events in patients assigned to the rofecoxib group compared with placebo, whereas the APC trial presented a significant increase in the risk of serious $\mathrm{CV}$ events, including $\mathrm{CV}$-related death, myocardial infarction, stroke, and heart failure, compared with placebo. ${ }^{67,68}$

\section{Bone healing}

NSAIDs are commonly prescribed in musculoskeletal trauma for relieving pain and inflammation. Several animal studies have indicated that NSAID use was associated with delayed union of fractures and poor outcome. ${ }^{34,70}$ However, a considerable number of studies failed to reproduce this effect. ${ }^{34,70}$ Controversial data have also been derived from clinical studies, with some authors failing to show an impairment of fracture union, whereas others showed significant risk for delayed union and nonunion. ${ }^{34,70}$ In terms of the clinical studies, Davis and Ackroyd studied the effect of 2-week administration of flurbiprofen on Colles' fractures. ${ }^{71}$ No impairment on fracture healing union was noted. Similarly, other studies found no effect on osteopenia after Colles' fracture, and aseptic loosening after hip replacement was found. ${ }^{72,73}$ However, Giannoudis et al showed a strong association between long-term NSAID administration and nonunion development. ${ }^{74}$ In patients undergoing spinal fusion, a time- and dose-dependent effect was found with short-term and low-dose administration to have no effect on the rate of nonunion, whereas long-term postoperative doses of NSAIDs had an increased risk of developing nonunion. ${ }^{75,76}$

\section{Other side effects}

Nonaspirin NSAIDs are metabolized in the liver, and small increases in transaminases can occur. ${ }^{77}$ As a result, NSAID administration in patients with cirrhotic liver diseases should be avoided; as such, patients are at greater risk of variceal bleeding, worsening of hepatic function, and kidney failure. ${ }^{77}$ However, NSAIDs rarely cause hepatic damage, and any hepatic effects are usually reversible. ${ }^{78}$ NSAIDs with more potential for hepatic problems include droxicam, clometacin, and sulindac. ${ }^{79}$

Aspirin and other NSAIDs can trigger or exacerbate asthma, resulting in violent attacks. This effect can be attributed to COX-1 inhibition by NSAIDs, which causes alteration of arachidonic acid metabolism, resulting in overproduction of leukotrienes. ${ }^{80,81}$ Upper and lower airway eosinophil infiltration is a key feature in this clinical syndrome. ${ }^{80}$ The prevalence of aspirin-sensitive asthmatics is $\sim 21 \%$, a figure that doubles in patients with nasal polyps or recurrent sinusitis. ${ }^{80}$ Fatal episodes have also been reported; therefore, NSAID and aspirin administration should be avoided in these patients. ${ }^{77}$ Recent data suggest that selective COX-2 inhibitors do not elicit bronchospasm and may be a safer option. ${ }^{80}$

In children with acute febrile viral illness, studies have demonstrated an association between aspirin use and Reye's syndrome. ${ }^{82}$ Reye's syndrome is an acute metabolic 
encephalopathy and liver inflammation triggered by damage to cellular mitochondria. ${ }^{82,83}$ The risk of Reye's syndrome is rare and decreases with age; it becomes extremely rare by the late teenage years. ${ }^{83}$ Other NSAIDs can trigger Reye's syndrome; therefore, an inborn error of metabolism has been suggested. ${ }^{82-84}$ Current advice in many countries, including the US, suggests that aspirin should not be given to those under the age of 16 years, unless specifically indicated in Kawasaki disease or in the prevention of blood clot formation.

NSAID use has also been contraindicated during the last 6-8 weeks of pregnancy. ${ }^{77,85,86}$ NSAID administration during this period should be avoided in order to prevent prolonged gestation from inhibition of prostaglandin synthesis, premature closure of the ductus arteriosus, and antiplatelet activity causing maternal and fetal complications. ${ }^{77,85}$ Recent data suggest that NSAID use throughout pregnancy increases the risk of miscarriages and birth defects. ${ }^{86}$ In breastfeeding women, most NSAIDs can be used safely, although concerns are raised for dipyrone and aspirin at a dosage $>100 \mathrm{mg} /$ day. ${ }^{87}$ In childhood, parents should be educated regarding correct NSAID dosing and storage in childproof containers to prevent accidental NSAID overdose in children.

\section{Conclusions}

NSAIDs have been used successfully for centuries for the alleviation of pain and inflammation and continue to be used every day by millions of patients worldwide. The recent discovery of the well-praised COX-2 selective inhibitors showed that these agents have a more complex effect not solely bound to analgesia and inflammation. Overall, clinicians should be aware of their potential side effects, and prophylactic treatment should be sought especially in patients with risk factors. Further research in the field will, without question, bring innovative pharmaceutical developments with a considerable spectrum of use.

\section{Disclosure}

The authors report no conflicts of interest in this work.

\section{References}

1. Rainsford KD. Anti-inflammatory drugs in the 21 st century. Subcell Biochem. 2007;42:3-27.

2. Steinmeyer J. Pharmacological basis for the therapy of pain and inflammation with nonsteroidal anti-inflammatory drugs. Arthritis Res. 2000;2(5):379-385.

3. Vane JR. Inhibition of prostaglandin synthesis as a mechanism of action for aspirin-like drugs. Nat New Biol. 1971;231(25):232-235.

4. Talley NJ, Evans JM, Fleming KC, Harmsen WS, Zinsmeister AR, Melton LJ 3rd. Nonsteroidal antiinflammatory drugs and dyspepsia in the elderly. Dig Dis Sci. 1995;40(6):1345-1350.
5. Laine L. Approaches to nonsteroidal anti-inflammatory drug use in the high-risk patient. Gastroenterology. 2001;120(3):594-606.

6. Goldblatt WM. A depressor substance in seminal fluid. J Soc Chem Ind. 1933;52:1056-1057.

7. McAdam BF, Catella-Lawson F, Mardini IA, Kapoor S, Lawson JA, FitzGerald GA. Systemic biosynthesis of prostacyclin by cyclooxygenase (COX)-2: the human pharmacology of a selective inhibitor of COX-2. Proc Natl Acad Sci U S A. 1999;96(1): 272-277.

8. Warner TD, Mitchell JA. Cyclooxygenases: new forms, new inhibitors, and lessons from the clinic. FASEB J. 2004;18(7):790-804.

9. Bertolini A, Ottani A, Sandrini M. Dual acting anti-inflammatory drugs: a reappraisal. Pharmacol Res. 2001;44(6):437-450.

10. Heller A, Koch T, Schmeck J, van Ackern K. Lipid mediators in inflammatory disorders. Drugs. 1998;55(4):487-496.

11. Vane JR, Bakhle YS, Botting RM. Cyclooxygenases 1 and 2. Annu Rev Pharmacol Toxicol. 1998;38:97-120.

12. Vonkeman HE, van de Laar MA. Nonsteroidal anti-inflammatory drugs: adverse effects and their prevention. Semin Arthritis Rheum. 2010;39(4):294-312.

13. Garavito RM, DeWitt DL. The cyclooxygenase isoforms: structural insights into the conversion of arachidonic acid to prostaglandins. Biochim Biophys Acta. 1999;1441(2-3):278-287.

14. Whelton A. Nephrotoxicity of nonsteroidal anti-inflammatory drugs: physiologic foundations and clinical implications. Am J Med. 1999;106(5B):13S-24S

15. Trautman MS, Edwin SS, Collmer D, Dudley DJ, Simmons D, Mitchell MD. Prostaglandin H synthase-2 in human gestational tissues: regulation in amnion. Placenta. 1996;17(4):239-245.

16. Vane JR, Botting RM. Mechanism of action of nonsteroidal antiinflammatory drugs. Am J Med. 1998;104(3A):2S-8S.

17. Van Ryn J, Pairet M. Clinical experience with cyclooxygenase-2 inhibitors. Inflamm Res. 1999;48(5):247-254.

18. Choi SH, Aid S, Bosetti F. The distinct roles of cyclooxygenase-1 and -2 in neuroinflammation: implications for translational research. Trends Pharmacol Sci. 2009;30(4):174-181.

19. Crofford LJ, Lipsky PE, Brooks P, Abramson SB, Simon LS, van de Putte LB. Basic biology and clinical application of specific cyclooxygenase-2 inhibitors. Arthritis Rheum. 2000;43(1):4-13.

20. Teeling JL, Cunningham C, Newman TA, Perry VH. The effect of non-steroidal anti-inflammatory agents on behavioural changes and cytokine production following systemic inflammation: implications for a role of COX-1. Brain Behav Immun. 2010; 24(3):409-419.

21. Botting R, Ayoub SS. COX-3 and the mechanism of action of paracetamol/acetaminophen. Prostaglandins Leukot Essent Fatty Acids. 2005;72(2):85-87.

22. Berenbaum F. COX-3: fact or fancy? Joint Bone Spine. 2004;71(6): $451-453$.

23. Green GA. Understanding NSAIDs: from aspirin to COX-2. Clin Cornerstone. 2001;3(5):50-60.

24. Warner TD, Giuliano F, Vojnovic I, Bukasa A, Mitchell JA, Vane JR. Nonsteroid drug selectivities for cyclo-oxygenase-1 rather than cyclo-oxygenase-2 are associated with human gastrointestinal toxicity: a full in vitro analysis. Proc Natl Acad Sci U S A. 1999;96(13):7563-7568.

25. Brooks P, Emery P, Evans JF, et al. Interpreting the clinical significance of the differential inhibition of cyclooxygenase-1 and cyclooxygenase-2. Rheumatology (Oxford). 1999;38(8):779-788.

26. Beck A, Salem K, Krischak G, Kinzl L, Bischoff M, Schmelz A. Nonsteroidal anti-inflammatory drugs (NSAIDs) in the perioperative phase in traumatology and orthopedics effects on bone healing. Oper Orthop Traumatol. 2005;17(6):569-578.

27. Gajraj NM. The effect of cyclooxygenase-2 inhibitors on bone healing. Reg Anesth Pain Med. 2003;28(5):456-465.

28. Ebell MH. NSAIDs vs opiates for pain in acute renal colic. Am Fam Physician. 2004;70(9):1682. 
29. Holdgate A, Pollock T. Systematic review of the relative efficacy of non-steroidal anti-inflammatory drugs and opioids in the treatment of acute renal colic. BMJ. 2004;328(7453):1401.

30. Lundstam SO, Leissner KH, Wåhlander LA, Kral JG. Prostaglandin-synthetase inhibition with diclofenac sodium in treatment of renal colic: comparison with use of a narcotic analgesic. Lancet. 1982;1(8281):1096-1097.

31. Stacher G, Steinringer H, Schneider S, Mittelbach G, Winklehner S, Gaupmann G. Experimental pain induced by electrical and thermal stimulation of the skin in healthy man: sensitivity to 75 and $150 \mathrm{mg}$ diclofenac sodium in comparison with $60 \mathrm{mg}$ codeine and placebo. Br J Clin Pharmacol. 1986;21(1):35-43.

32. Kantor T, Cavaliere MB, Hopper M, Roepke S. A double-blind parallel comparison of ketoprofen, codeine, and placebo in patients with moderate to severe postpartum pain. J Clin Pharmacol. 1984;24(5-6):228-234.

33. O’Neill WM, Hanks GW, Simpson P, Fallon MT, Jenkins E, Wesnes K. The cognitive and psychomotor effects of morphine in healthy subjects: a randomized controlled trial of repeated (four) oral doses of dextropropoxyphene, morphine, lorazepam and placebo. Pain. 2000;85(1-2):209-215.

34. Pountos I, Georgouli T, Blokhuis TJ, Pape HC, Giannoudis PV. Pharmacological agents and impairment of fracture healing: what is the evidence? Injury. 2008;39(4):384-394.

35. Duellman TJ, Gaffigan C, Milbrandt JC, Allan DG. Multi-modal, pre-emptive analgesia decreases the length of hospital stay following total joint arthroplasty. Orthopedics. 2009;32(3):167.

36. Hebl JR, Dilger JA, Byer DE, et al. A pre-emptive multimodal pathway featuring peripheral nerve block improves perioperative outcomes after major orthopedic surgery. Reg Anesth Pain Med. 2008;33(6):510-517.

37. Massey T, Derry S, Moore RA, McQuay HJ. Topical NSAIDs for acute pain in adults. Cochrane Database Syst Rev. 2010;(6):CD007402.

38. Buchbinder R. Topical NSAIDs provide effective relief of acute musculoskeletal pain compared to placebo, with no increase in risk of adverse effects. Evid Based Med. 2010;15(6):177-178.

39. Abrams GJ, Solomon L, Meyers OL. A long-term study of diclophenac sodium in the treatment of rheumatoid arthritis and osteo-arthrosis. S Afr Med J. 1978;53(12):442-445.

40. Kirchheiner B, Trang L, Wollheim FA. Diclophenax sodium (Voltaren) in rheumatoid arthritis: a double-blind comparison with indomethacin and placebo. Int J Clin Pharmacol Biopharm. 1976;13(4):292-297.

41. Chan FK, Lanas A, Scheiman J, Berger MF, Nguyen H, Goldstein JL. Celecoxib versus omeprazole and diclofenac in patients with osteoarthritis and rheumatoid arthritis (CONDOR): a randomised trial. Lancet. 2010;376(9736):173-179.

42. Chen YF, Jobanputra P, Barton P, et al. Cyclooxygenase-2 selective non-steroidal anti-inflammatory drugs (etodolac, meloxicam, celecoxib, rofecoxib, etoricoxib, valdecoxib and lumiracoxib) for osteoarthritis and rheumatoid arthritis: a systematic review and economic evaluation. Health Technol Assess. 2008;12(11):1-278, iii.

43. Poddubnyy D, Song IH, Sieper J. A systematic comparison of rheumatoid arthritis and ankylosing spondylitis: non-steroidal antiinflammatory drugs. Clin Exp Rheumatol. 2009;27(4 Suppl 55): S148-S151.

44. Maksymowych WP. Update on the treatment of ankylosing spondylitis. Ther Clin Risk Manag. 2007;3(6):1125-1133.

45. O'Brien JR. Effect of salicylates on human platelets. Lancet. 1968;1(7557):1431.

46. Gollapudi RR, Teirstein PS, Stevenson DD, Simon RA. Aspirin sensitivity: implications for patients with coronary artery disease. JAMA. 2004;292(24):3017-3023.

47. Richardson CM, Sharma RA, Cox G, O’Byrne KJ. Epidermal growth factor receptors and cyclooxygenase- 2 in the pathogenesis of non-small cell lung cancer: potential targets for chemoprevention and systemic therapy. Lung Cancer. 2003;39(1):1-13.
48. Sandler AB, Dubinett SM. COX-2 inhibition and lung cancer. Semin Oncol. 2004;31(2 Suppl 7):45-52.

49. Bennett A, Del Tacca M. Proceedings: prostaglandins in human colonic carcinoma. Gut. 1975;16(5):409.

50. Kashfi K, Rigas B. Is COX-2 a 'collateral' target in cancer prevention? Biochem Soc Trans. 2005;33(Pt 4):724-727.

51. Szekely CA, Zandi PP. Non-steroidal anti-inflammatory drugs and Alzheimer's disease: the epidemiological evidence. CNS Neurol Disord Drug Targets. 2010;9(2):132-139.

52. Cotlier E. Aspirin effect on cataract formation in patients with rheumatoid arthritis alone or combined with diabetes. Int Ophthalmol. 1981;3(3):173-177.

53. Van Heyningen R, Harding JJ. A case-control study of cataract in Oxfordshire: some risk factors. Br J Ophthalmol. 1988;72(11): 804-808.

54. Laine L. The role of proton pump inhibitors in NSAID-associated gastropathy and upper gastrointestinal symptoms. Rev Gastroenterol Disord. 2003;3 Suppl 4:S30-S39.

55. Larkai EN, Smith JL, Lidsky MD, Sessoms SL, Graham DY. Dyspepsia in NSAID users: the size of the problem. J Clin Gastroenterol. 1989;11(2):158-162.

56. Holvoet J, Terriere L, van Hee W, Verbist L, Fierens E, Hautekeete ML. Relation of upper gastrointestinal bleeding to non-steroidal antiinflammatory drugs and aspirin: a case-control study. Gut. 1991;32(7): 730-734.

57. García Rodríguez LA, Jick H. Risk of upper gastrointestinal bleeding and perforation associated with individual non-steroidal antiinflammatory drugs. Lancet. 1994;343(8900):769-772.

58. Singh G, Ramey DR, Morfeld D, Shi H, Hatoum HT, Fries JF. Gastrointestinal tract complications of nonsteroidal anti-inflammatory drug treatment in rheumatoid arthritis. A prospective observational cohort study. Arch Intern Med. 1996;156(14):1530-1536.

59. Silverstein FE, Graham DY, Senior JR, et al. Misoprostol reduces serious gastrointestinal complications in patients with rheumatoid arthritis receiving nonsteroidal anti-inflammatory drugs. A randomized, double-blind, placebo-controlled trial. Ann Intern Med. 1995;123(4):241-249.

60. Winkelmayer WC, Waikar SS, Mogun H, Solomon DH. Nonselective and cyclooxygenase-2-selective NSAIDs and acute kidney injury. Am J Med. 2008;121(12):1092-1098.

61. Schneider V, Lévesque LE, Zhang B, Hutchinson T, Brophy JM. Association of selective and conventional nonsteroidal antiinflammatory drugs with acute renal failure: a population-based, nested case-control analysis. Am J Epidemiol. 2006;164(9):881-889.

62. Clive DM, Stoff JS. Renal syndromes associated with nonsteroidal antiinflammatory drugs. $N$ Engl J Med. 1984;310(9): 563-572.

63. Griffin MR, Yared A, Ray WA. Nonsteroidal antiinflammatory drugs and acute renal failure in elderly persons. Am J Epidemiol. 2000;151(5):488-496.

64. Aw TJ, Haas SJ, Liew D, Krum H. Meta-analysis of cyclooxygenase-2 inhibitors and their effects on blood pressure. Arch Intern Med. 2005;165(5):490-496.

65. Chan CC, Reid CM, Aw TJ, Liew D, Haas SJ, Krum H. Do COX-2 inhibitors raise blood pressure more than nonselective NSAIDs and placebo? An updated meta-analysis. J Hypertens. 2009; 27(12):2332-2341.

66. Nussmeier NA, Whelton AA, Brown MT, et al. Complications of the COX-2 inhibitors parecoxib and valdecoxib after cardiac surgery. N Engl J Med. 2005;352(11):1081-1091.

67. Bresalier RS, Sandler RS, Quan H, et al. Cardiovascular events associated with rofecoxib in a colorectal adenoma chemoprevention trial. N Engl J Med. 2005;352(11):1092-1102.

68. Solomon SD, McMurray JJ, Pfeffer MA, et al. Cardiovascular risk associated with celecoxib in a clinical trial for colorectal adenoma prevention. N Engl J Med. 2005;352(11):1071-1080. 
69. Graham DJ, Campen D, Hui R, et al. Risk of acute myocardial infarction and sudden cardiac death in patients treated with cyclo-oxygenase 2 selective and non-selective non-steroidal anti-inflammatory drugs: nested case-control study. Lancet. 2005;365(9458):475-481.

70. Pountos I, Giannoudis PV, Jones E, et al. NSAIDs inhibit in vitro MSC chondrogenesis but not osteogenesis. J Cell Mol Med. Jan 112010. [Epub ahead of print].

71. Davis TR, Ackroyd CE. Non-steroidal anti-inflammatory agents in the management of Colles' fractures. Br J Clin Pract. 1988;42(5):184-189.

72. Adolphson P, Abbaszadegan H, Jonsson U, Dalen N, Sjoberg HE, Kalen S. No effects of piroxicam on osteopenia and recovery after Colles' fracture. A randomized, double-blind, placebo-controlled, prospective trial. Arch Orthop Trauma Surg. 1993;112(3):127-130.

73. Wurnig C, Schwameis E, Bitzan P, Kainberger F. Six-year results of a cementless stem with prophylaxis against heterotopic bone. Clin Orthop Relat Res. 1999;(361):150-158.

74. Giannoudis PV, MacDonald DA, Matthews SJ, Smith RM Furlong AJ, de Boer P. Nonunion of the femoral diaphysis. The influence of reaming and non-steroidal anti-inflammatory drugs. J Bone Joint Surg Br. 2000;82(5):655-658.

75. Reuben SS, Ablett D, Kaye R. High dose nonsteroidal antiinflammatory drugs compromise spinal fusion. Can J Anaesth. 2005;52(5):506-512.

76. Reuben SS, Ekman EF. The effect of cyclooxygenase-2 inhibition on analgesia and spinal fusion. J Bone Joint Surg Am. 2005;87(3):536-542.

77. Risser A, Donovan D, Heintzman J, Page T. NSAID prescribing precautions. Am Fam Physician. 2009;80(12):1371-1378.

78. Licata A, Calvaruso V, Cappello M, Craxì A, Almasio PL. Clinical course and outcomes of drug-induced liver injury: nimesulide as the first implicated medication. Dig Liver Dis. 2010;42(2):143-148.
79. Lapeyre-Mestre M, de Castro AM, Bareille MP, et al. Non-steroidal anti-inflammatory drug-related hepatic damage in France and Spain: analysis from national spontaneous reporting systems. Fundam Clin Pharmacol. 2006;20(4):391-395.

80. Szczeklik A. Aspirin-induced asthma: a tribute to John Vane as a source of inspiration. Pharmacol Rep. 2010;62(3):526-529.

81. Sabry EY. The prevalence of aspirin-induced asthma in Saudian asthmatic patients. Allergol Immunopathol (Madr). 2010;38(4): $181-186$.

82. Gosalakkal JA, Kamoji V. Reye syndrome and reye-like syndrome. Pediatr Neurol. 2008;39(3):198-200.

83. Fitzgerald DA. Aspirin and Reye syndrome. Paediatr Drugs. 2007;9(3):205-206

84. Schrör K. Aspirin and Reye syndrome: a review of the evidence. Paediatr Drugs. 2007;9(3):195-204.

85. Damase-Michel C, Christaud J, Berrebi A, Lacroix I, Montastruc JL. What do pregnant women know about non-steroidal anti-inflammatory drugs? Pharmacoepidemiol Drug Saf. 2009;18(11):1034-1038.

86. Vroom F, van den Berg PB, de Jong-van den Berg LT. Prescribing of NSAIDs and ASA during pregnancy; do we need to be more careful? Br J Clin Pharmacol. 2008;65(2):275-276.

87. Bar-Oz B, Bulkowstein M, Benyamini L, et al. Use of antibiotic and analgesic drugs during lactation. Drug Saf. 2003;26(13):925-935.

88. McEvoy GK. AHFS Drug Information. Bethesda (MD): American Society of Health-System Pharmacists; 2004:534-720.

89. British National Formulary. 52nd ed. London (UK): British Medical Association and Royal Pharmaceutical Society of Great Britain; 2005:513-522.

International Journal of Interferon, Cytokine and Mediator Research

Dovepress

\section{Publish your work in this journal}

The International Journal of Interferon, Cytokine and Mediator Research is an international, peer-reviewed, open-access, online journal. The focus of the journal is to publish original research, reports, editorials, reviews and commentaries on all aspects of interferon, cytokine and mediators of inflammation from labora- tory science to therapeutic indications and clinical studies. The manuscript management system is completely online and includes a very quick and fair peer-review system, which is all easy to use. Visit http://www.dovepress.com/testimonials.php to read real quotes from published authors. 